\title{
ALFABETIZAÇÃO EDUCAÇÃO DE JOVENS E ADULTOS: O PROCESSO DE CONSTRUÇÃO DA ESCRITA
}

\author{
Alciclea Ramos dos Santos ${ }^{1}$ \\ Ana Paula de Abreu Costa de Moura ${ }^{2}$ \\ Jacqueline Cardoso Ferreira ${ }^{3}$
}

A Educação de Jovens e Adultos (EJA) mesmo se constituindo como uma modalidade de ensino, a partir da LDB no 9394/96, ainda traz uma série de desafios: desde romper com a visão da EJA dentro de uma perspectiva compensatória e não como um direto, o não reconhecimento das especificidades dos sujeitos que estão inseridos nesta modalidade e a falta de formação específica dos educadores.

Muitos dos profissionais que atuam na educação de jovens e adultos não tiveram a formação adequada nos cursos de pedagogia ou nos cursos de magistério. A formação acadêmica ainda é exígua, visto que grande parte das universidades brasileiras não oferece nenhuma disciplina nos cursos de Pedagogia voltada para atuação nesta modalidade e, quando esta já faz parte da grade curricular, muitas vezes, só aparece no final do curso, não conseguindo aprofundar nas questões políticas e pedagógicas da modalidade. O mesmo ocorre nos demais cursos de licenciatura, pois a maioria direciona o olhar do futuro professor para a educação de crianças e quando existem disciplinas de EJA, estas são eletivas ou optativas. A ausência destas discussões nos cursos de formação inicial traz grande fragilidade para a atuação docente e faz com que os professores tenham como primeiro contato com a EJA a prática de sala de aula.

A ausência de discussão da EJA nos espaços formativos soma-se à falta de materiais didáticos a serem utilizados em salas de aula, principalmente quando atuam na alfabetização. Muitas vezes, o alfabetizador reproduz atividades

\footnotetext{
${ }^{1}$ Pós graduanda em Eduacação de Jovens e Adultos pelo Instituto Federal de Educação, Ciência e Tecnologia do Rio de Janeiro. clea_rj@yahoo.com.br

2 Professora Doutora da Faculdade de Educação da Universidade Federal do Rio de Janeiro. anapaulaabreumoura@gmail.com

${ }^{3}$ Especialista em Educação de Jovens e Adultos pela Universidade Federal do Rio de Janeiro. jacflower_88@hotmail.com
} 
adaptadas de antigas cartilhas de alfabetização de crianças, e trazem palavras repetitivas, descontextualizadas e esvaziadas de sentindo, sem buscar construir uma reflexão crítica e sem levar em consideração os sujeitos envolvidos no processo e os conhecimentos que esses trazem, como ressalta Moura:

Sem a devida qualificação, os professores passam a desenvolver a prática pedagógica ignorando as especificidades e peculiaridades dos sujeitos em processo de escolarização. Utilizam metodologias (técnicas, recursos e atividades) sem qualquer significado para os alunos-trabalhadores, desconsiderando o contexto e a historicidade desses sujeitos (MOURA, 2009, p.46)

Junta-se a isso a ideia de que para alfabetizar alguém basta ser alfabetizado, como vimos em muitas campanhas de alfabetização, que "convocavam" a população alfabetizada para alfabetizar alguém. Essa ideia traz consigo a desqualificação da profissão docente, uma vez que deixa claro a não necessidade de preparação desse sujeito para atuar como professor. Ignora também a complexidade do ato alfabetizador e, mais ainda, a complexidade do ato de alfabetizar jovens e adultos, pois para além do necessário conhecimento da língua e das diferentes metodologias alfabetizadoras, trabalhar com jovens e adultos exige 0 conhecimento de suas especificidades.

É necessário mais do que apenas ser alfabetizado. É preciso que o alfabetizador tenha clareza do seu fazer pedagógico, do como ensinar, mas também que ele tenha compreensão de como o aluno aprende e de que conhecimentos da leitura e da escrita ele já construiu. Não raro quando discutimos alfabetização de jovens e adultos a referência feita aos sujeitos da EJA parte do que lhes falta: "não tem autonomia com a leitura e com a escrita"; "não tem conhecimentos da linguagem matemática"; "não fazem uso da norma culta". O próprio nome analfabeto é construído pelo conceito de ausência. Contudo, acreditamos ser necessário olhar para esses sujeitos com o olhar de quem deseja ver toda a potencialidade que eles têm.

Como esse aluno circulou pela sociedade, ocupando diferentes papéis sociais, onde de alguma forma utilizam a leitura e a escrita, mesmo não sendo alfabetizado? Que conhecimentos da língua escrita esses alunos em processo de alfabetização já construíram? Que recursos utilizam para chegar a diferentes endereços, fazer distintos registros? As respostas a essas questões, são 
necessárias para que se possa elaborar um material específico a esta modalidade, levando em consideração os sujeitos e as suas especificidades.

Neste sentido, o Laboratório de Investigação Extensão e Ensino da Educação de Jovens e Adultos da Faculdade de Educação, que tem como espaço de intervenção o Programa Integrado da UFRJ para Educação de Jovens e Adultos - uma ação da Extensão Universitária - desenvolve uma pesquisa que tem como objetivo investigar como o aluno jovem, adulto e idoso em processo de alfabetização constrói sua escrita, visto que suas leituras de mundo precedem a leitura da palavra (FREIRE, 1996).

\section{CAMINHOS METODOLÓGICOS}

O trabalho de investigação traz uma abordagem de cunho qualitativo, onde é utilizada a metodologia da pesquisa participante (Thiollent, 2003), articulando os movimentos de olhar, pensar e agir, onde a coleta de informações e o mapeamento das situações, nos fornecem elementos para a reflexão e interpretação dos fatos, possibilitando elaborar formas de intervenção e avaliação. Nesse sentido, a pesquisa busca identificar modos de resolução de problemas concretos e possibilita também construir conhecimentos de alcance teórico e conceitual. Partindo dessa premissa, os pesquisadores do programa de extensão universitária, estavam inseridos em seis classes de alfabetização, localizadas em favelas do entorno da Cidade Universitária, com alunos de faixa etária entre 19 e 70 anos.

Nas classes de alfabetização, o olhar para a prática alfabetizadora estava direcionado para identificar as ocorrências na escrita que eram comuns a vários alunos e as ocorrências individuais, com o objetivo de identificar elementos para a elaboração de materiais didáticos específicos e contextualizados, que auxiliassem os educadores em suas aulas e promovessem um avanço no processo de ensinoaprendizagem dos educandos. As ocorrências individuais eram trabalhadas diretamente na relação professor aluno e para as ocorrências comuns a vários alunos, a equipe buscou elaborar atividades para serem desenvolvidas com 0 coletivo. O que estava claro para a equipe é que em toda e qualquer atividade é necessário ter clareza da intencionalidade e do objetivo que se quer alcançar.

O desenvolvimento deste trabalho de pesquisa pressupôs o olhar para os sujeitos da EJA, a partir do acompanhamento de sala de aula, buscando coletar pistas, observar nos detalhes mais negligenciáveis, como o aluno constrói seu 
conhecimento da leitura e da escrita. Fazendo o movimento que Freire (1994) chamou de "leitura de classes como se fossem textos":

Se, para a leitura de textos, necessitamos de instrumentos auxiliares de trabalho como dicionários de vários tipos e enciclopédias, também para a 'leitura' de classes, como se fossem textos, precisamos de instrumentos menos fáceis de usar. Precisamos, por exemplo, de bem observar, bem comparar, bem intuir, bem imaginar, bem liberar nossa sensibilidade, crer nos outros mas não demasiado no que pensamos dos outros. (Paulo Freire, 1994:68)

Contudo, aceitar o convite de Freire não é uma tarefa fácil, pois na perspectiva da pesquisa participante também fazemos parte desse texto da sala de aula. Se por um lado a inserção nas classes e a aproximação dos alunos possibilitam leituras que um pesquisador externo não conseguiria ter, por outro, em alguns momentos nos vemos tão imbricados na ação que a reflexão pode ser mais difícil.

Nessa construção metodológica, o elemento a ser investigado surge da prática e serve para reflexões e formulações, que qualificam o trabalho no cotidiano escolar. No movimento de compreensão da prática educativa, a construção de instrumentos que possibilitem acompanhar o desenvolvimento dos alunos cumpre, pelo menos duas funções essenciais: 1) a reflexão do professor sobre o universo da sala de aula e os saberes presentes neles; 2) organização e planejamento das atividades a serem desenvolvidas em sala de aula. Temos assim, um movimento de retroalimentação, onde a ação extensionista, provoca a pesquisa e traz elementos para novas intervenções e também para pensarmos a formação docente do futuro alfabetizador, materializando assim, a indissociabilidade entre ensino-pesquisaextensão.

Assim, diante das indagações encontradas em sala de aula, a equipe realizou uma revisão de literatura, onde percebemos que muitos dos estudos que existem sobre a aprendizagem da leitura e da escrita são voltados para crianças, deixando uma lacuna a respeito do sujeito jovem e adulto. Os referenciais teóricos (Lemle, 2001, Leal, 2004, Carvalho, 2001) que nortearam a investigação reconhecem a complexidade do processo de alfabetização, e reforçam nossa afirmativa que não basta estar alfabetizado para saber alfabetizar. Pelo contrário, a prática alfabetizadora requer conhecimentos específicos de nossa língua, das abordagens metodológicas e das especificidades da Educação de Jovens Adultos. 
A revisão de literatura trouxe esclarecimentos, mas trouxe ainda mais indagações. Sendo assim, focamos o olhar sobre os conhecimentos do sistema de escrita alfabética - SEA- (Leal, 2004) que precisam ser construídos pelos alunos. A equipe da pesquisa, construiu então, um instrumento que buscava permitir ao alfabetizador identificar que conhecimentos da leitura e da escrita, os alfabetizandos já haviam construído. De posse do instrumento, a equipe elaborou atividades didáticas, numa perspectiva interdisciplinar, que permitissem identificar os itens a serem observados e que contemplassem questões de compreensão, interpretação e específicas do SEA. Após a elaboração do material, a equipe da pesquisa retornou para as salas de aula de posse do material.

Em sala de aula, observamos as distintas itinerâncias dos alunos na construção da escrita, alguns movimentos que poderiam ser considerados como erros, eram considerados, na perspectiva que olhávamos, como movimentos de construção da leitura e da escrita. Como, por exemplo, um dos alunos que ao escrever a palavra CERVEJA, representou-a graficamente como CVA. $\mathrm{Na}$ perspectiva do nosso olhar, o aluno ao fazer isso já mostra que identifica que a palavra tem três sílabas (ainda que não tenha clareza que toda sílaba necessariamente tem que ter uma vogal) e as representa graficamente, com três letras, em duas dessas letras, ele utiliza os nomes das próprias letras para representar a sílaba e na última (JA), o aluno usa o A, que é o pico silábico da vogal, portanto mais perceptível, para fazer a representação.

Um outro aluno ao se referir ao nome Maria, coloca que "MAIA E TU12 OTE" (Maria é tudo forte). Quando indagado sobre a construção da palavra TU12, ele diz que sabe que tudo tem o DO, mas ele não lembra como escreve-lo, por isso resolveu colocar o numeral 12 , porque sabe que esse numeral tem o som do DO. A resposta do aluno, nos permite compreender a tática que ele vai utilizando diante de situações da língua escrita, para as quais ele não tem respostas imediata e nos leva a refletir também sobre o processo de avaliação educacional e como este muitas vezes não considera as construções dos alunos.

Os exemplos citados acima e outros que observamos nos dão pistas da forma como os alunos, diante da não autonomia com a leitura e com a escrita, comparam, excluem, reorganizam, ordenam, categorizam, reformulam, comprovam e formulam hipóteses. Neste sentido, o diálogo tão defendido por FREIRE (1987) é essencial na prática educativa, pois se estivéssemos trabalhando apenas com a 
perspectiva do certo ou errado, não teríamos tido a oportunidade de ouvir do aluno a itinerância de sua construção. Nesse contexto, a pergunta formulada por FREIRE (1996) ganha extrema relevância: como trabalhar não importa em que campo da alfabetização, da produção econômica, em projetos cooperativos ou na saúde, sem ir conhecendo as manhas com que os grupos produzem sua própria sobrevivência?

Diante disso, fizemos uma reflexão junto com os alfabetizadores acerca dos resultados encontrados e a elaboração de novas atividades, que atendessem aos princípios básicos do sistema de escrita alfabética, que os alunos ainda não se apropriaram, visando assim, o aprimoramento das práticas pedagógicas desenvolvidas no Programa. A elaboração conjunta de atividades pela equipe da pesquisa e os alfabetizadores envolveu momentos de profundas reflexões, que uniram o olhar sobre a realidade dos alunos e o conhecimento sobre os princípios da escrita alfabética. Em cada atividade, a explicitação dos objetivos e intenções tinham que estar presentes.

Ao verificar os dados, constatou-se a complexidade do ato de alfabetizar, pois os educandos em processo de alfabetização refletem nas suas escritas as táticas construídas para suas leituras de mundo e sua inserção nos espaços que exigem a leitura da palavra. Neste sentido, a atividade que buscava fazer com que o aluno direcionasse sua atenção para a construção da palavra e não somente para o seu significado, nos trouxe grandes pistas sobre como esse aluno compreende a palavra escrita. Numa atividade que propunha a associação de uma palavra com outra que apresentasse uma rima foi bastante reveladora. Na primeira atividade, a orientação era explicar ao educando o que era rima e em seguida, ler para ele um trecho da música "Cotidiano", de Chico Buarque de Holanda, que traz uma discussão do cotidiano, exemplificando com palavras como: igual e pontual; parar e levar; feijão e não.

Após as exemplificações, lia-se para o educando o enunciado (pois muitos ainda se encontravam em fase inicial da escrita) e, pedia que o aluno se atentasse ao som, rimando uma palavra com outra. Considerando que um dos princípios básicos do sistema de escrita é que a relação do SEA é com a pauta sonora e não com propriedades dos conceitos dos objetos apresentados, o objetivo da atividade era perceber qual a relação que o aluno da EJA estabelecia no sistema de escrita. 
Um dos aspectos observados nesta atividade, é que o aluno ao ser solicitado a encontrar palavras que rimam, estabelece uma relação semântica e não sonora, o que nos leva a pontuar a indissociabilidade entre a leitura de mundo e a leitura da palavra. Podemos constatar este resultado em algumas falas dos educandos, que ao rimar correr com não, explicavam com as seguintes frases: "Para não correr muito." "Ninguém aguenta correr o dia todo sem parar, ou senão, a noite está estourando". Já na rima calo com ralo, a fala foi "Se tiver muito tempo de joelho, faz um calo. Se ralo muito faz calo".

Convidados a identificar num grupo de palavras (mato, força, colher) quais que rimavam com a palavra mulher, representada com pela figura de Maria Bonita, muito alunos rimaram a palavra mulher, com a palavra força. No espaço onde tinha que justificar as respostas, muitos destacavam a força de Maria Bonita, deixando claro que estavam priorizando uma associação semântica e não a relação com a pauta sonora.

Nas construções escritas, uma outra questão que esteve muito presente foi a dificuldade de utilizar diferentes padrões silábicos que rompessem com o padrão silábico universal Consoante Vogal - CV. Muitas foram as palavras onde as letras que rompiam com este padrão foram suprimidas. A observação deste fato apontou para uma dificuldade em identificar as diferentes estruturas silábicas, que pode estar relacionada também com a prática alfabetizadora, uma vez que os alfabetizadores, muitas vezes, buscam trabalhar a estrutura silábica CV, de preferência com correspondência biunívoca e deixam para um segundo momento o trabalho com as outras estruturas silábicas. A identificação desta questão, nos trouxe elementos para pensarmos atividades dirigidas, na busca de incorporação desses outros padrões silábicos à escrita dos alunos.

Numa outra atividade, a proposta era trabalhar com a separação de sílabas, onde o pesquisador explicava aos alfabetizandos que eles deveriam separar as sílabas e depois circular as vogais. O objetivo era observar se os alunos atentavam para as diferentes estruturas silábicas e que toda sílaba contém, pelo menos, uma vogal. Ao analisar a resposta dos alfabetizandos nesta atividade, observou-se a dificuldade acerca da apropriação das diferentes estruturas silábicas, visto que quando solicitado a separar sílabas, em que se encontrava padrões diferentes do padrão universal Consoante-Vogal - CV, o aluno não o fazia de forma correta, criando suas próprias estratégias, que em alguns exemplos remetem ao 
padrão CV, que, exaustivamente, é trabalhado pelos professores no início da alfabetização, dificultando a apropriação de outras estruturas.

Dentre as estratégias utilizadas pelos alunos encontramos; a separação de sílabas por pares: MU- LH- ER; a não aceitação de uma sílaba com três letras: NÃO; e o não reconhecimento de que toda sílaba é composta por, pelo menos, uma vogal: ES-PE-RAN-DO. Vale ressaltar que para esta pesquisa foram 36 alunos de diferentes turmas do entorno da Cidade Universitária da Universidade Federal do Rio de Janeiro, como Maré, Parada de Lucas, Ilha do Governador e Ramos.

\section{CONSIDERAÇÕES FINAIS}

A pesquisa desenvolvida tem contribuído para o trabalho dos alfabetizadores, destacando a importância de se pensar o aluno de EJA como um sujeito que constrói conhecimento e, a partir de suas necessidades, cria mecanismos para solucionar possíveis situações de insegurança no cotidiano. O olhar investigativo do docente para a prática educativa possibilita o aperfeiçoamento do processo pedagógico a ser realizado e elaboração de materiais didáticos com intencionalidade e qualidade, possibilitando ao seu alfabetizando o avanço na apropriação do SEA. Sendo assim, o trabalho em desenvolvimento converge ao ideal, defendido por Paulo Freire, (1997) de que a prática educativa deve ser compreendida criticamente, esteja ela relacionada a uma pós-graduação de uma universidade ou a uma classe de alfabetização.

Nesta pesquisa, percebe-se a relação indissociável entre teoria e prática. Onde a teoria está incorporada na prática e a prática traz novos elementos para questionarmos, investigarmos ou confirmarmos essa teoria, num movimento de ação-reflexão-ação, não ficando restrito unicamente a uma superficialidade do fazer pedagógico, mas se debruçando sobre as pistas e os indícios a prática pedagógica.

\footnotetext{
Não há ensino sem pesquisa e pesquisa sem ensino. Esses que-fazeres se encontram um no corpo do outro. Enquanto ensino continuo buscando, reprocurando. Ensino porque busco, porque indaguei, porque indago e me indago. Pesquiso para constatar, constatando, intervenho, intervindo educo e me educo. Pesquiso para conhecer o que ainda não conheço e comunicar ou anunciar a novidade. (FREIRE,1996, p.29)
}

Neste sentido, a indagação é uma marca da prática docente e o olhar do professor precisa estar direcionado para os educandos enquanto sujeitos 
encarnados que, trazem histórias de vida, constroem e trazem seus saberes para a sala de aula, deixando presentes nas suas escritas. A utilização de materiais didáticos com questões do cotidiano dos alunos também torna-se um instrumento facilitador na prática docente, pois os educandos ao refletirem sobre sua realidade, se sentem mais seguros para desenvolver suas escritas.

Deste modo, as atividades propostas puderam verificar quais conhecimentos sobre o Sistema de Escrita Alfabética os educandos já tinham se apropriado e reafirmar que todos somos seres inacabados, tanto educandos, quanto nós educadores. Precisamos enquanto profissionais da educação incorporar o papel de pesquisador, aquele que não se conforma com o óbvio, mas que lê nas entrelinhas buscando por "respostas" que possam dar um melhor suporte às necessidades do educando.

O grande desafio da escola, principalmente na educação de jovens e adultos é construir uma prática que respeite, resgate e valorize os saberes que os alunos trazem e que não só aproxime o saber da escola desse saber, como também permita aos alunos, o acesso a novos conhecimentos. Assim, desenvolver uma prática educativa baseada nos conhecimentos prévios dos educandos sobre os princípios do sistema de escrita alfabética é, sem dúvida, de uma importância inquestionável.

\section{REFERÊNCIAS}

CARVALHO, Marlene. Guia prático do alfabetizador. São Paulo: Editora Ática, 2001.

FREIRE, Paulo. Pedagogia do Oprimido. Paulo Freire. - 17 ed. rev. e atual. -Rio de Janeiro, Ed. Paz e Terra, 1987.

educativa. São Paulo, SP: Paz e Terra, 1996.

Pedagogia da autonomia: saberes necessários à prática

Professora sim, tia não: cartas a quem ousa ensinar. São Paulo:

Olho D’ Água, 1997. 
A importância do ato de ler: em três artigos que se completam / Paulo Freire. - 51르 ed. - São Paulo: Cortez, 2011. - (Coleção questões da nossa época; v.22)

LEAL. Telma Ferraz. A aprendizagem dos princípios básicos do sistema alfabético: Por que é importante sistematizar o ensino. In: ALBUQUERQUE, Eliana Borges Correia de. A alfabetização de jovens e adultos em uma perspectiva de letramento. Belo Horizonte: Autêntica, 2004.

LEMLE, Miriam. Guia Teórico do Alfabetizador. 15. ed. São Paulo: Ática, 2001.

MOURA, Tania Maria de Melo. Dossiê temático Educação de pessoas jovens, adultas e idosas Práxis Educacional Vitória da Conquista. v. 5, n. 7 p. 45-72 jul./dez. 2009. Formação de Educadores de Jovens e Adultos: Realidade, Desafios e Perspectivas Atuais.

THIOLLENT, Michel; CASTELO BRANCO, Alba Lúcia; GUIMARÃES, Regina Guedes Moreira; ARAÚJO FILHO, Targino de. (org.). Extensão universitária: conceitos, métodos e práticas. Rio de Janeiro, 2003. 